\title{
Stable isotope informed genome-resolved metagenomics uncovers potential trophic interactions in rhizosphere soil
}

Evan P. Starr ${ }^{1}$, Shengjing Shi ${ }^{2}$, Steven J. Blazewicz ${ }^{3}$, Benjamin J. Koch ${ }^{4,5}$, Alexander J. Probst ${ }^{6}$, Bruce A. Hungate ${ }^{4,5}$, Jennifer Pett-Ridge ${ }^{3}$, Mary K. Firestone ${ }^{7,8, *}$ and Jillian F. Banfield $7,8,9,10,11, *$

${ }^{1}$ Department of Plant and Microbial Biology, University of California, Berkeley, CA, USA

${ }^{2}$ Lincoln Science Centre, AgResearch Ltd, Christchurch, New Zealand

${ }^{3}$ Physical and Life Sciences Directorate, Lawrence Livermore National Laboratory, Livermore, CA, USA

${ }^{4}$ Department of Biological Sciences, Northern Arizona University, Flagstaff, AZ, USA

${ }^{5}$ Center for Ecosystem Science and Society, Northern Arizona University, Flagstaff, AZ, USA

${ }^{6}$ Biofilm Center, University of Duisburg-Essen, Essen, Germany

${ }^{7}$ Department of Environmental Science, Policy, and Management, University of California, Berkeley, CA, USA

${ }^{8}$ Earth and Environmental Sciences, Lawrence Berkeley National Laboratory, Berkeley, CA, USA

${ }^{9}$ Department of Earth and Planetary Science, University of California, Berkeley, CA, USA

${ }^{10}$ Innovative Genomics Institute, Berkeley, CA, USA

${ }^{11}$ Chan Zuckerberg Biohub, San Francisco, CA, USA

*Corresponding authors: mkfstone@berkeley.edu and jbanfield@berkeley.edu 


\begin{abstract}
The functioning, health, and productivity of soil is intimately tied to a complex network of interactions, particularly in plant root-associated rhizosphere soil. We conducted a stable isotope-informed, genome-resolved metagenomic study to trace carbon from Avena fatua grown in a ${ }^{13} \mathrm{CO}_{2}$ atmosphere into soil. We collected paired rhizosphere and non-rhizosphere soil at six and nine weeks of plant growth and extracted DNA that was then separated by density using gradient centrifugation. Thirty-two fractions from each sample were grouped by density, sequenced, assembled, and binned to generate 55 unique microbial genomes that were $>70 \%$ complete. The complete $18 \mathrm{~S}$ rRNA sequences of several micro-eukaryotic bacterivores and fungi were enriched in ${ }^{13} \mathrm{C}$. We generated several circularized bacteriophage (phage) genomes, some of which were the most labelled entities in the rhizosphere. CRISPR locus targeting connected one of these phage to a Burkholderiales host predicted to be a plant pathogen. Another highly labeled phage is predicted to replicate in a Catenulispora sp., a possible plant growth-promoting bacterium. We searched the genomes for traits known to be used in interactions involving bacteria, micro-eukaryotes and plant roots and found that heavily isotopically-labeled bacteria have the ability to modulate plant signaling hormones, possess numerous plant pathogenicity factors, and produce toxins targeting micro-eukaryotes. Overall, ${ }^{13} \mathrm{C}$ stable isotope-informed genome-resolved metagenomics revealed that very active bacteria often have the potential for strong interactions with plants and directly established that phage can be important agents of turnover of plant-derived carbon in soil.
\end{abstract}

\title{
Introduction
}

Plant-derived carbon provides the energetic basis for an intricate web of life in soil, among the world's most complex microbial ecosystems. Heterotrophic soil organisms are sustained primarily by the carbon that is fixed by plants, released into the rhizosphere, and eventually flows into the surrounding soil, feeding other organisms or becoming soil organic matter.

The soil ecosystem is characterized by interactions between organisms across trophic levels, which may direct the fate of plant-derived carbon in soil. These interactions have been difficult to investigate because of the tremendous physical and chemical heterogeneity of soil and resulting vast biological diversity. Much of the recent work on soil microbiology has been sequence-based and focused on generating inventories of bacteria and archaea using 16S rRNA gene fragments $(1,2)$ or fungi using Internal Transcribed Spacer region sequencing $(3,4)$. Since DNA extracted from soil includes genes from virtually all organisms present, it is possible to use soil shotgun metagenome sequencing to profile soil communities, potentially with genomic resolution. This is important because genomes provide not only phylogenetic information but also a cache of functional predictions. However, relatively few studies have achieved genomic 
resolution of soil, largely due to enormous strain complexity and relatively even abundance levels (5-9). Bacterial genomes encode a huge variety of known and unknown genes, including those that comprise biosynthetic gene clusters (BGC). Such biosynthetic pathways hold technological relevance but are also fundamental for soil ecology, as their products could mediate inter-organismal interactions, including offensive interactions via antibiotics, interorganism and mineral-interactions via siderophores, and signaling compounds $(10,11)$. While there has been a surge of interest in viral diversity and ecology, there have been relatively few studies documenting bacterial-phage interactions in soil (12-14). Also present in soil are fungi, protists and larger organisms that have been documented via 18S rRNA gene sequencing (15, $16)$ and more classical methods $(17,18)$. While some studies have documented bipartite interactions, such as fungi-bacteria $(19,20)$, bacteria-phage $(12,21)$, plant-fungi $(22,23)$, detailing complex multi-trophic interactions in soil remains a huge challenge.

Lacking from most studies of soil to date is information about how nutrients flow among soil community members. Stable isotope probing (SIP) has been used for decades to identify interactions and follow the flow of elements through communities. SIP studies have been conducted in a variety of ecosystems, including hot springs and the animal gut, using a range of isotopes and labelled substrates (24-27). SIP studies can utilize carbon fixing organisms to generate biomass and complex mixes of compounds to investigate general processes such as decomposition of litter or life in the rhizosphere (28-31). Stable isotopes can also be traced between trophic levels allowing the study of microbial predation and phage activity $(32,33)$. A recently developed variant, quantitative SIP (qSIP), makes these measurements possible at the individual or population genome scale. This is facilitated by comparing the taxon-specific density for each sequenced entity in the labelled and unlabeled fractions $(34,35)$. From this data we estimated the gross growth rate of organisms on labelled carbon substrates.

To better understand the soil inter-organismal interactions that are initiated by the input of plant-derived rhizodeposits, we combined stable isotope probing and genome resolved metagenomics. We grew common wild oat grass, Avena fatua, for six and nine weeks in a ${ }^{13} \mathrm{CO}_{2}$ enriched atmosphere and tracked the isotopically enriched plant carbon as it was released to the surrounding soil community via exudation, decay of root biomass, and direct biotic transfer through pathogen attack. Over the course of our experiment, we expected the plant-derived carbon to move through trophic levels, including primary consumers, predators, parasites, saprotrophs, and their phage. By separating extracted DNA based on density we determined which organisms consumed the isotopically heavy plant-derived carbon and incorporated it into their genomes during replication. We used assembly and binning of genomes to analyze the encoded genes at the organismal level and identify traits that may reflect how organisms might interact with one another. We targeted interaction signatures such as genes for the production 
of plant hormones and modulation of hormone concentrations, secretion systems, and secondary metabolites. Assembled genomes enabled the prediction of whether an organism is a plant growth-promoting bacteria (PGPB) or a pathogen $(36,37)$.

\section{Results}

\section{Labelling}

A. fatua plants were grown in a continuously regenerated ${ }^{13} \mathrm{CO}_{2}$ environment. One plant was harvested after six weeks and a second after nine weeks. Samples were collected from the rhizosphere (within $2 \mathrm{~mm}$ of the root) as well as soil regions from which roots were excluded (see Methods); these are referred to as "bulk" samples. We also collected a sample of soil prior to planting. This sample is also denoted as "bulk." After six weeks of growth, the plant shoots were highly labelled ( 94 atom $\%{ }^{13} \mathrm{C}$ ) (38). DNA was extracted from both the rhizosphere and bulk soil samples. We compared the density separation of the rhizosphere DNA to the bulk soil DNA to identify un-enriched DNA (light), a mixture of enriched and unenriched DNA (middle), and highly ${ }^{13} \mathrm{C}$-enriched (heavy) then these fractions were shotgun sequenced (Supplemental figure 1 and Supplemental table 1). After assembly of the individual metagenomes, it appeared that the heavier fractions (middle and heavy) had larger assemblies and higher N50 values than the assemblies of the more complex light fractions (Supplemental table 1).

\section{Soil community}

Given that it is currently impossible to bin genomes for all organisms in a soil sample, yet relatively extensive reconstruction of genome fragments is possible, we used an assembled marker gene approach to approximate microbial community composition. For this analysis we used ribosomal protein S3 (rpS3), which is in single copy on bacterial and archaeal genomes and has been used to profile microbial communities for phylogeny and abundance $(39,40)$. From each sample we identified the rpS3 and dereplicated the sequences to a level of $99 \%$ nucleic 
acid identity (41). The resulting 314 distinct rpS3 sequences represent bacteria from both well characterized and understudied clades (Figure 1).

To study community dynamics across samples and fractions we mapped the reads from each sample and fraction to each scaffold containing the rpS3 gene. We used the coverage of the

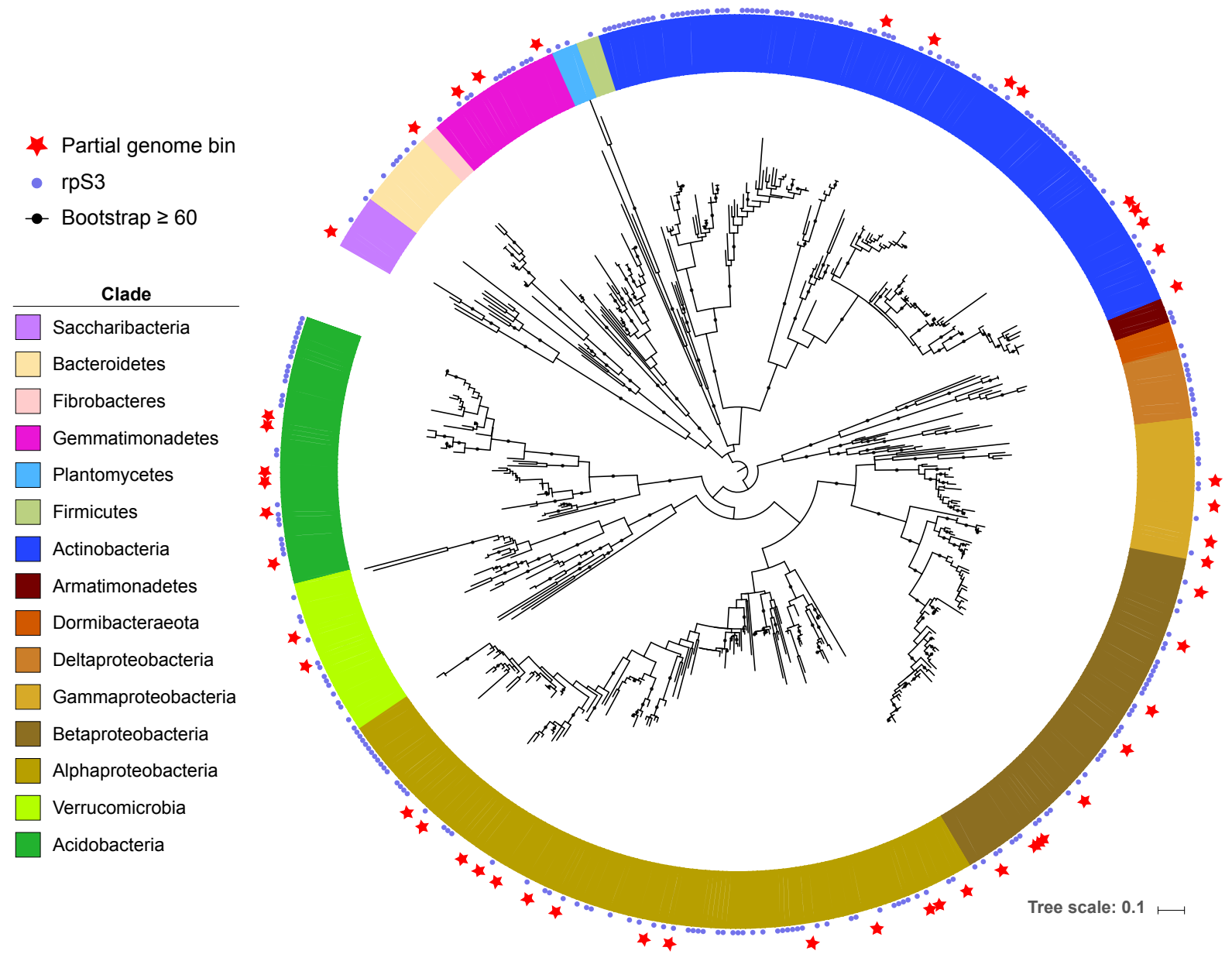

Figure 1. Phylogenetic tree of bacterial rpS3. Soil and rhizosphere-derived metagenomic bacterial bins with an rpS3 gene and unbinned scaffolds are marked. Bacterial clades are highlighted in different colors.

scaffolds as a proxy for the organism's relative abundance. The fractions and samples show a visual community separation (Figure 2). The bulk samples separate into a light fraction (tan) cluster and a heavier fraction (brown) cluster. This is due to lower-GC organism's DNA in the light fraction and the higher-GC DNA in the heavier fraction. The bulk light fraction and rhizosphere light fraction samples group together. The rhizosphere middle fraction separates from the light fractions (both rhizosphere light and bulk light fractions) and the bulk soil heavier fraction as it contains DNA from the high-GC organisms that did not incorporate the label and the lower-GC organisms that were labelled sufficiently to increase the density of their DNA. 
Finally, the rhizosphere heavy fractions separate from all other fractions. The bacteria present in this sample are almost entirely high-GC organisms that incorporated ${ }^{13} \mathrm{C}$ into their DNA.

From our 12 metagenomes, we reconstructed and binned 55 dereplicated, partial bacterial genomes that were $\geq 70 \%$ complete with $\leq 10 \%$ contamination, as measured by the inventory of 51 single copy genes (Figure 3; Supplemental figure 2).

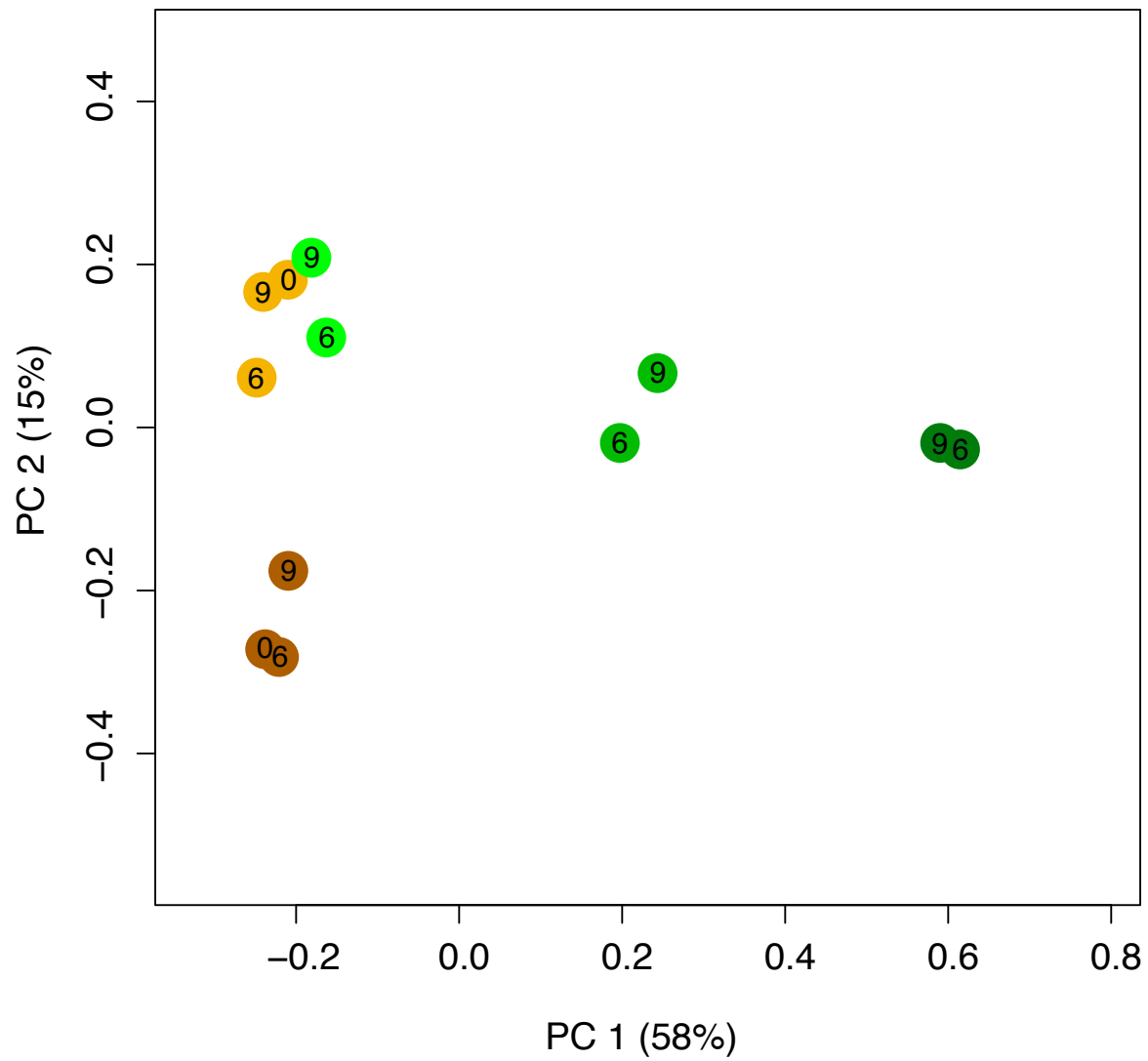

Figure 2. PCoA of bacterial rpS3 from different samples and SIP fractions. The brown dots represent bulk samples (the dark brown are the heavier fractions and the tan are light fractions). Green dots represent rhizosphere SIP fractions: the darker the green the heavier the sample. Numbers inside the dots correspond to the week of sampling.
In addition to bacteria, we detected a number of eukaryotes and phage. We reconstructed 27 complete 18S rRNA gene sequences from soil eukaryotes and used them for identification (Figure 3; Supplemental figure 3). Apart from the $A$. fatua and a single moss, the remaining 25 micro-eukaryotes fall into a variety of soil clades including Amoebozoa, Fungi, Metazoa (nematodes and rotifers), Rhizaria, and Alveolata. We also identified phage-derived DNA in our samples and reconstructed 10 complete, circularized phage genomes (Figure $\mathbf{3}$ ).

We used quantitative stable isotope probing (qSIP) to estimate ${ }^{13} \mathrm{C}$ atom percent excess (APE) for each taxon $(34,35)$. The qSIP method relies on tracking the shift in density, calculated by coverage in the different

fractions, of a genome between unlabeled (bulk) and labelled (rhizosphere) samples. We mapped the reads of all samples against our dereplicated suite of 55 genome bins. We used the 


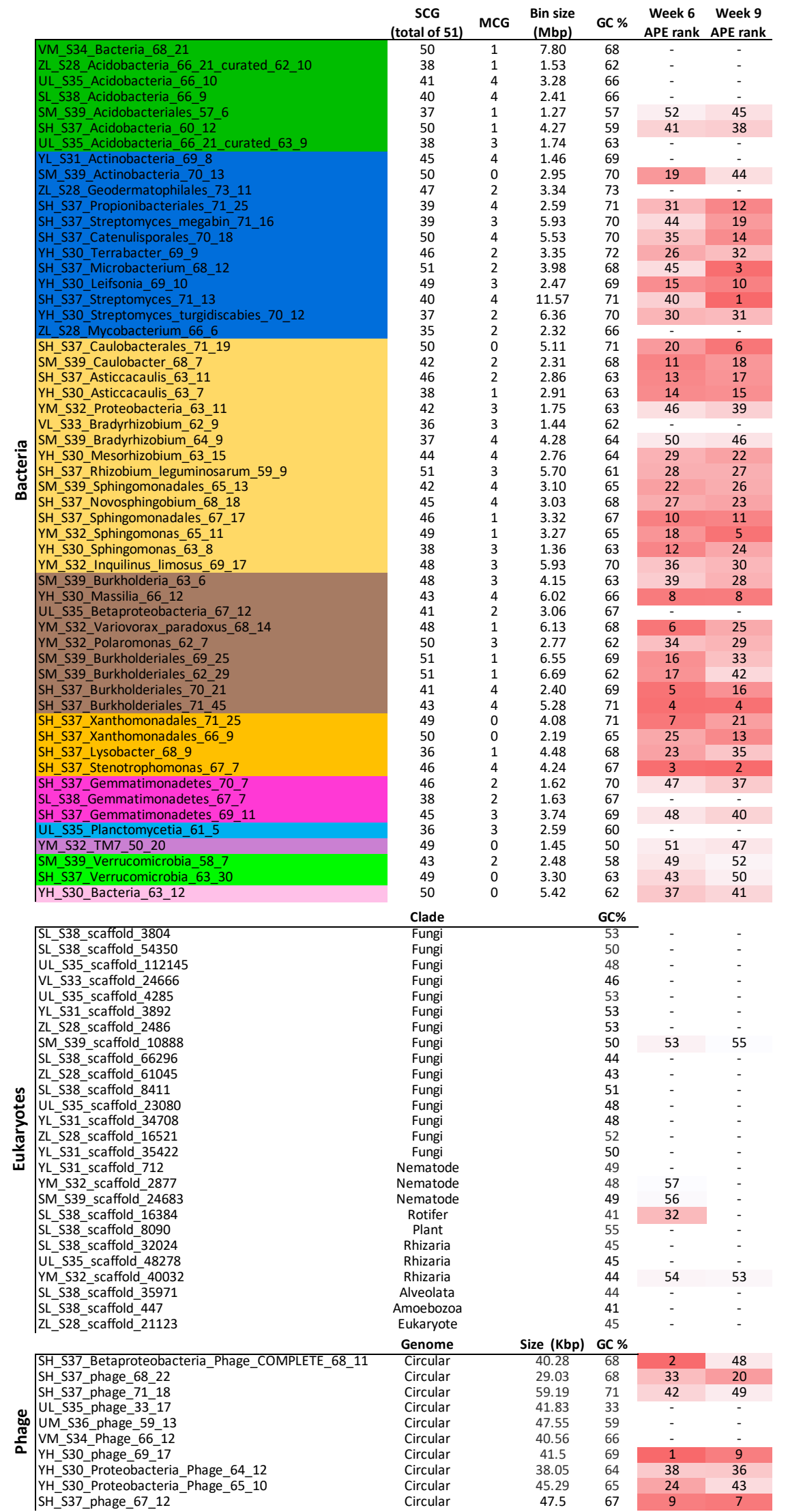

Figure 3. Genome and isotope labelling statistics. Genome statistics for the bacteria (colored by clade following the color scheme from Fig. 1), eukaryote scaffolds containing $18 \mathrm{~S}$ rRNA genes, and complete phage genomes. The rank APE (highlighted with red heat maps for each column) is derived from the qSIP calculations, and is shown in ascending order for week 6 and 9 . The bin completeness and contamination are presented as the number of 51 single copy genes (SCG) and number of multicopy genes (MCG).

coverage of the scaffolds containing the $18 \mathrm{~S}$ rRNA as a proxy for eukaryotic genome coverage. Because of the lack of replicates and small number of fractions we chose a conservative cutoff of $2.5 \%$ APE (see Methods), any entities with an APE higher than this cutoff were interpreted as having detectably incorporated the ${ }^{13} \mathrm{C}$ tracer (Figure 4). We report the rank in ascending order of APE for each sequence in Figure 3. Many of the phage we identified appear to be highly labelled. Bacteria were also highly labeled, and some of eukaryote sequences were labeled, although to a lesser degree than the bacterial genomes (Figure 4). 

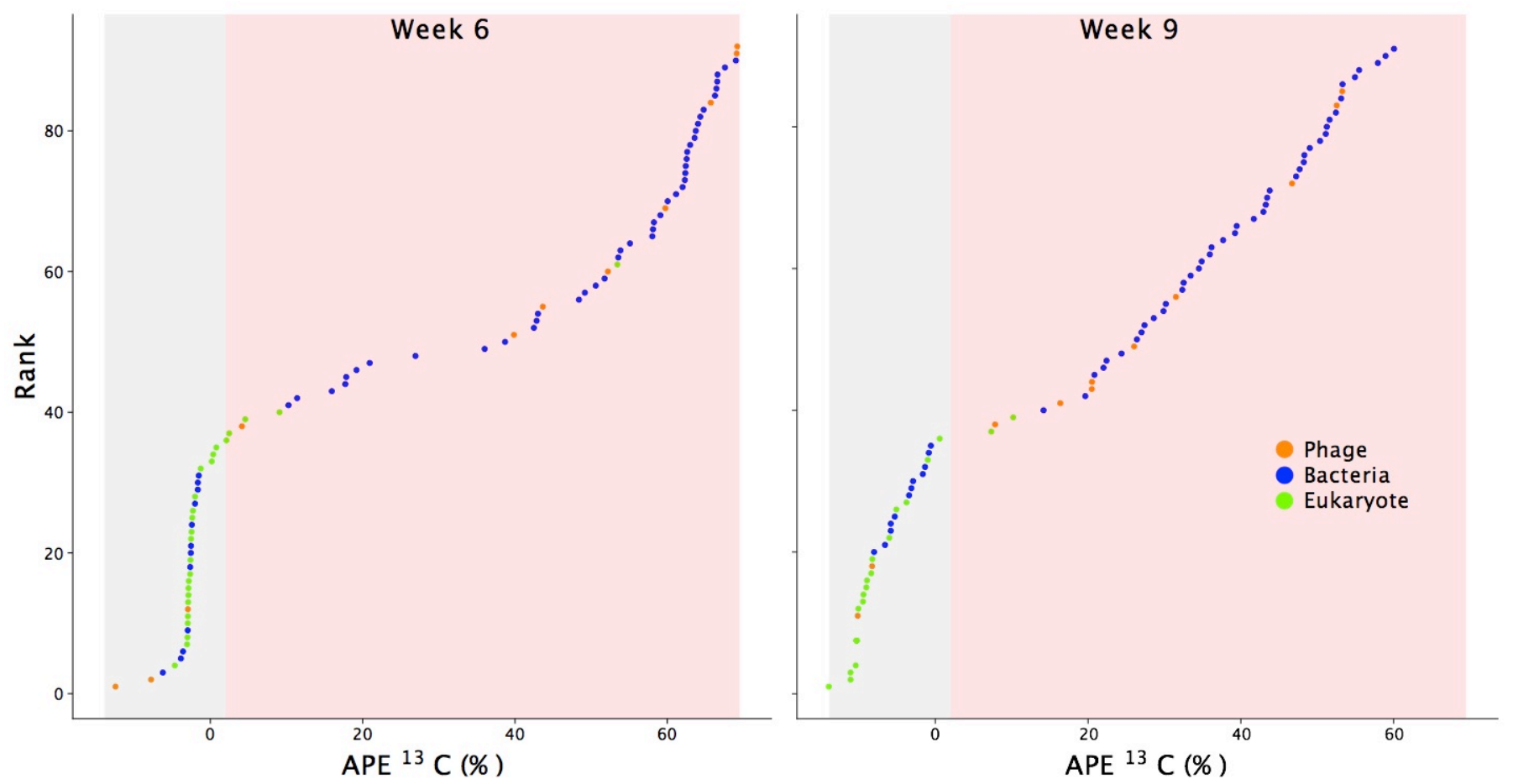

Figure 4. The rank of soil-derived phage genomes, bacterial genome bins, and scaffolds encoding eukaryotic $18 \mathrm{~S}$ rRNA genes in week 6 and 9 in order of their atom percent excess (APE) based on the qSIP calculations. The gray region indicates unlabeled entities and the red indicated predicted labelled DNA, the labelling cutoff is explained in the methods section.

We calculated the gross growth rate for each taxon on labelled carbon. These taxon-specific growth rate estimates can be thought of as a measure of which individual organismal populations in the rhizosphere grew on plant-derived carbon. The gross growth rates indicated bacterial and phage growth but limited eukaryotic growth on plant-derived carbon. Indeed, only a few specific bacteria and phage had high gross growth rates on plant derived-carbon, and many taxa showed little to no growth (Supplemental figure 4).

We analyzed our genomes for a suite of genome sequences that could code for pathways involved in inter-organismal interactions. The possible machineries involved in these interactions provide the foundation for a conceptual understanding of the carbon flow and multitrophic interactions in these soil samples, as shown in Figure 5.

\section{Plant-soil community}




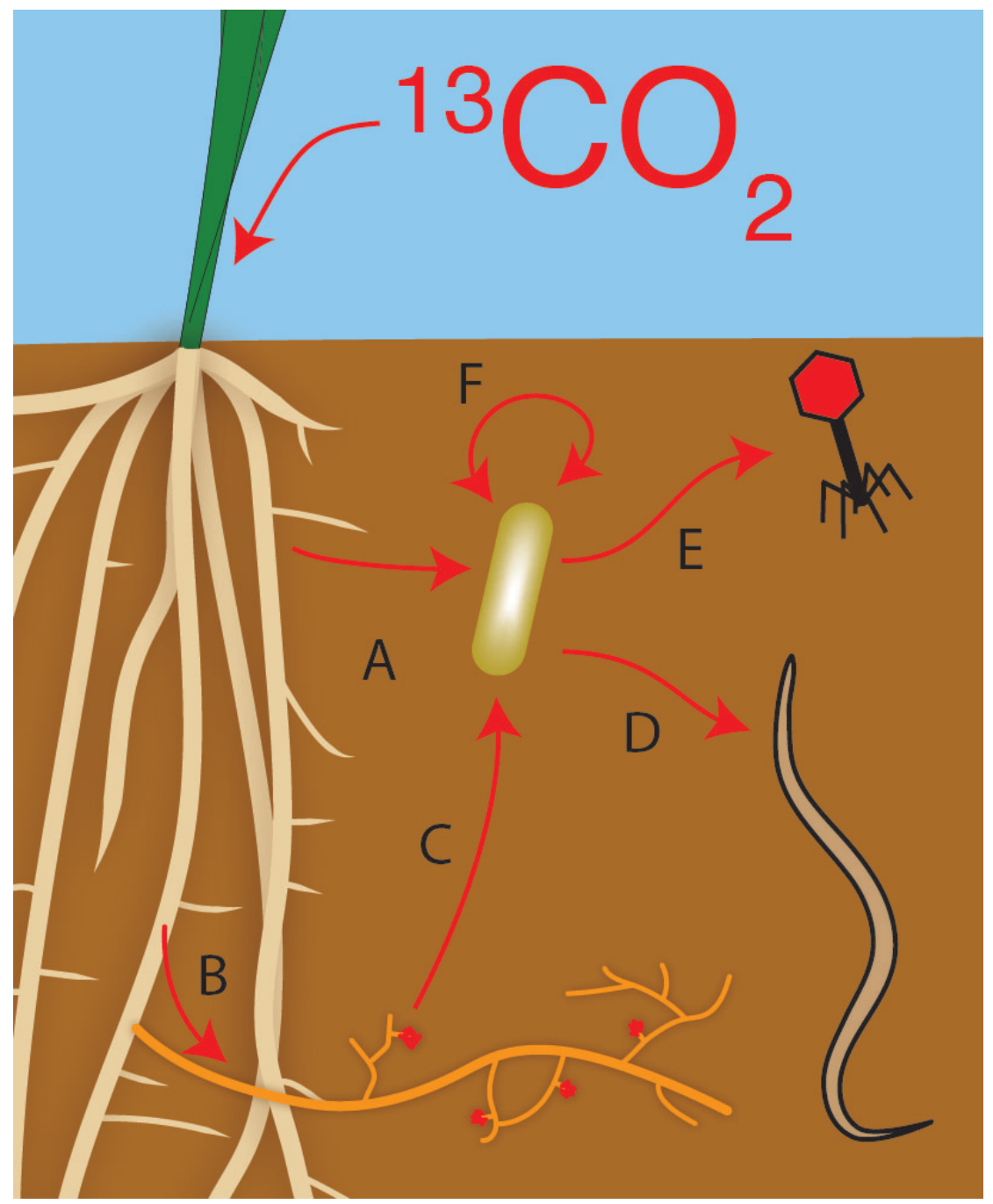

Figure 5. Conceptual diagram of carbon flow and community interactions in the rhizosphere. Red lines indicate possible flow of $13 \mathrm{C}$ label into and through DNA. Bacteria consume plant exudates or actively infect the plant to receive carbon (A). Fungi may also be infecting and/or decomposing dead plant material (B). Rhizosphere dwelling bacteria may be interacting with live fungi or breaking down dead fungal biomass (C). Bacterivorous microeukaryotes may have consumed rhizosphere bacteria. (D). Bacteriophage may have infected rhizosphere dwelling bacteria (E). Bacterial genomes were also rife with systems made for communication and competition between bacteria $(F)$.

Although plant-derived carbon is the main source of ${ }^{13} \mathrm{C}$ used by the soil community, other organisms may be able to fix $\mathrm{CO}_{2}$. However, we found no evidence for carbon fixation pathways in the bacterial genomes and the lack of density shift in the bulk samples indicates that this effect was undetectable (Supplemental figure 1). Many of the bacterial genomes encoding plant interaction mediating genes and pathways were highly labelled, suggesting an intimate relationship between the plant roots and bacteria.

Bacteria that are closely associated with plants may degrade plant infection signaling hormones to avoid detection during plant colonization. Many of the bacterial genomes we binned encoded the ability to hydrolyze salicylic acid (Figure 6), a common phenolic plant hormone used in pathogen defense signaling (42). However, this protein can also be used to degrade other phenolic compounds (43). Thus, we examined the nearby genomic regions for clues about the function of the gene. In one instance, the salicylate hydroxylase gene in the Microbacterium_68_12 genome is surrounded by a variety of glycosyl hydrolases and esterases that act on plant cell wall polymers. Additionally, many of the rhizosphere-dwelling organisms encode the ability to degrade another pathogen defense hormone, nitric oxide gas (44). 
bioRxiv preprint doi: https://doi.org/10.1101/2020.08.21.262063; this version posted August 21, 2020. The copyright holder for this preprint (which was not certified by peer review) is the author/funder, who has granted bioRxiv a license to display the preprint in perpetuity. It is made available under aCC-BY-ND 4.0 International license.

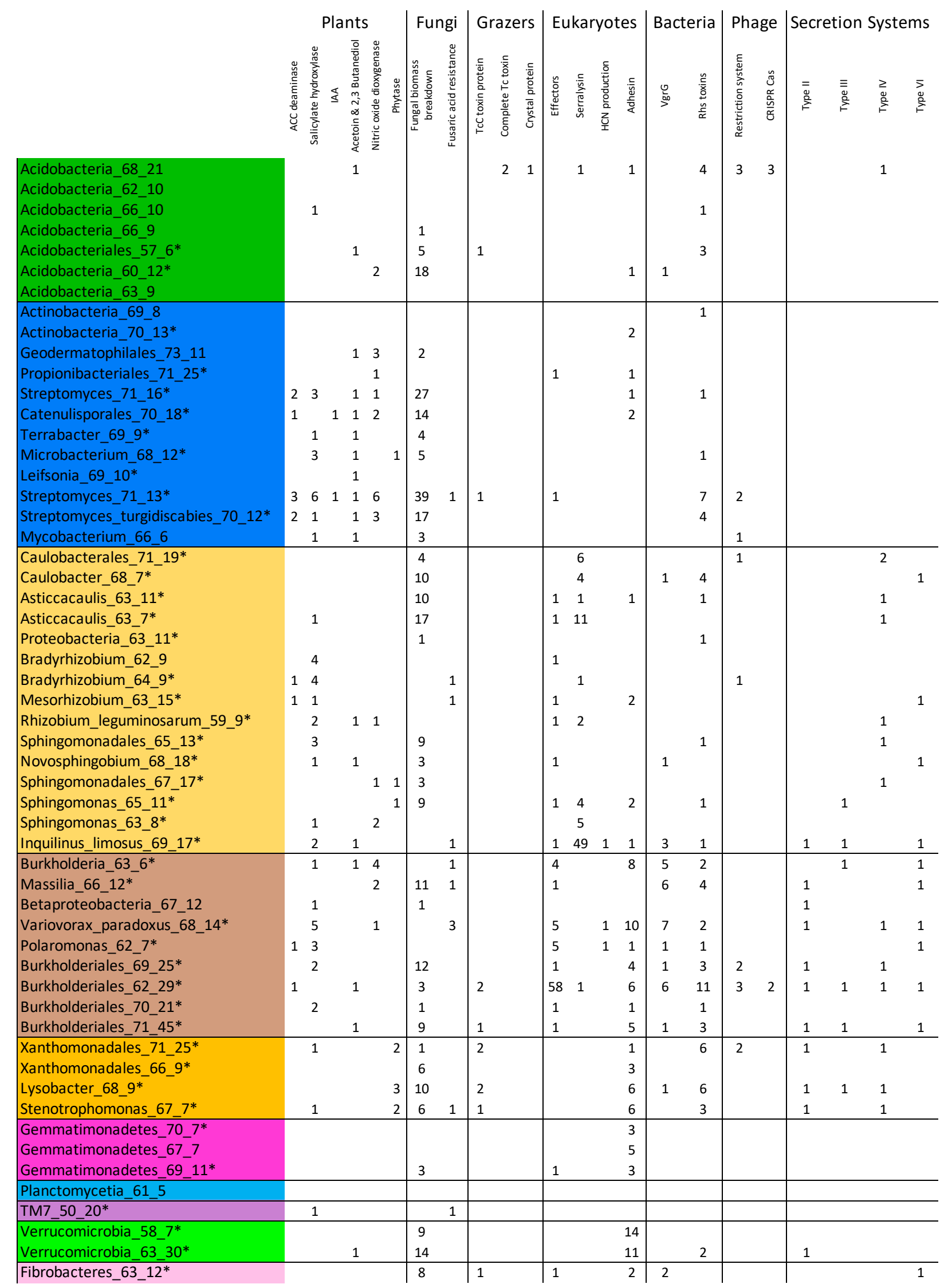

Figure 6. Possible inter-organismal interactions encoded on the bacterial genomes. Numbers indicate the number of individual genes or mostly complete pathways predicted to be used in inter-organismal interaction. Asterisks signify genome bins with detectable ${ }^{13} \mathrm{C}$ label. 
Some bacteria, especially PGPB, promote plant growth through the production of hormones and other compounds. Two of the bacterial genomes we reconstructed encoded the pathway for indole-3-acetic acid production, which increases plant growth and induces a variety of other physiological changes (Figure 6). Eight genomes encode 1-aminocyclopropane-1-carboxylate (ACC) deaminase (Figure 6), which prevents ACC from being converted to ethylene in the plant. However, ACC deaminase is also involved in the generation of propionate. In the Streptomyces_71_13 genome the ACC deaminase gene is surrounded by pectin lyases, pectinesterases, and a BGC. We identified 18 genomes with the pathways for the production of acetoin and/or 2,3-butanediol from pyruvate (Figure 6). These bacterially produced volatile organic compounds (VOCs) diffuse through soil and can act as growth-promoting factors and stimulate the plant systemic defense. Although these compounds increase resistance to plant pathogens, the pathway can also be involved in the anaerobic fermentation of glucose $(45,46)$.

Microbes can also promote plant growth through nutrient generation or mobilization. We did not identify any $\mathrm{N}_{2}$ fixing pathways in the genomes or on the unbinned scaffolds. Some PGPB are able to mobilize phosphorus for use by the plant, but these genes cannot be distinguished from central metabolism and common enzymes. However, microbially produced phytases release phosphorus from phytate, a phosphorus storage compound common in soil but inaccessible to mature plants (Figure 6) (47). Several of the genomes encoded biosynthetic pathways to produce siderophores (Supplemental figure 5). In addition to iron acquisition, siderophores can complex iron and other metals, thus promoting the release of phosphate from insoluble soil-associated minerals (48).

Some of the genomes appeared to encode secretion systems associated with bacteriaeukaryotic interactions. Six genomes encode multiple genes from type III secretion systems, which are known to be important in symbiotic colonization and infection of plants, fungi, singlecelled eukaryotes, and animals (49). We do not know the intended targets of the type III secretion systems because of the diversity of possible hosts. However, we identified 58 type III effector proteins with sequence homology to known plant pathogen effector proteins (mostly from Ralstonia, Pseudomonas and Xanthomonas) encoded on the Burkholderiales_62_29 genome (Figure 6). We also identified 13 genomes with probable type IV secretion systems (Figure 6), which are used in conjugation and injection of proteins or DNA/protein complexes into eukaryotic cells (50).

\section{Bacteria-Microeukaryotes}

Several of the bacterial genomes we assembled encode systems that may be intended for interacting with soil fungi. Ten of the partially complete genomes encoded fusaric acid 
resistance proteins, which protect from the antibiotic produced by Fusarium species (Figure 6). The Variovorax_paradoxus_68_14 genome appeared to encode three fusaric acid resistance modules; and, one was near an esterase and phospholipase $C$ which hydrolyzes phosphatidylcholine, an important fungal phospholipid (51). In one Streptomyces_71_13 genome the fusaric acid resistance module is near two glycoside hydrolases which may act on fungal cell walls. Included in this region is a ceramidase, which hydrolyzes glucosylceramides, a necessary metabolite for Fusarium pathogenesis and morphology (52). Another fungal antibiotic that these bacteria may encounter is penicillin, possibly produced by the Eurotiomycetes detected in the soil. Many bacterial genomes encoded penicillin resistance genes. Another possible indication of bacterial-fungal relationships is bacterial genes for decomposition of fungal compounds. The Streptomyces_71_13 genome encodes 39 enzymes that target fungal biomass, 30 of which have an identifiable secretion signal indicating they are exported extracellularly (Figure 6).

There is some evidence for bacterially produced defenses against grazing. The majority of work on bacterial grazing defense has focused on nematodes, but we assume similar strategies could be effective against other micro-eukaryotes. Bacteria often use extracellular polymeric substance (EPS) production, specific secondary metabolites, and active infection to deter grazing (53). EPS production is common in soil bacteria, but difficult to infer from genome information. One indication of EPS formation is the production of proteinaceous adhesins (54). Many of the genomes we investigated encoded adhesins, with two Verrucomicrobia (Verrucomicrobia_58_7 and Verrucomicrobia_63_30) and the Variovorax_paradoxus_68_14 genomes encoding the most (Figure 6). Several genomes encode the pathway to produce hydrogen cyanide (HCN; Figure 6). Eight of the genomes encode a insecticidal toxin subunit TcC which is lethal to certain insects, and possibly nematodes, on its own (Figure 6) (55). However, the Acidobacteria_68_21 genome encoded two complete Tc insecticidal toxin modules. In addition, in the same genome, we identified an insecticidal crystal protein related to the bt toxin from Bacillus thuringiensis (Figure 6).

\section{Bacteria-Bacteria}

In addition to bacterial interaction, cooperation, and competition with eukaryotes there may be indications of inter-bacterial connections in soil. Some of the best characterized mediators of inter-organismal interactions are signaling molecules including acyl-homoserine lactones, autoinducing peptides, indoles, gamma-butyrolactones, and a variety of other compounds (Supplemental figure 5). In addition, many genomes encode one or more quorum quenching genes, which may act to either degrade self-produced quorum molecules or as a means to disrupt other bacterial species communications. 
We identified a large number of biosynthetic gene clusters in the bacterial genomes, especially polyketide and nonribosomal peptide biosynthetic gene clusters (Supplemental figure 5). Several Streptomyces sp. encoded many BGCs and several Burkholderiales and Acidobacteria genomes also encoded a high number of secondary metabolite clusters, though this is less surprising in light of recent findings in other soils $(11,56)$. Some of the BGCs were related to known clusters, such as those that produce the broad spectrum antibiotic bicornutin from Xenorhabdus budapestensis and the sesquiterpene antibiotic albaflavenone, but many were novel. Some of the BGCs were located near other genes of interest for instance, the Streptomyces_turgidiscabies_70_12 genome encoded three BGCs near ten plant cell wall hydrolysis proteins. Evidence for competition between closely related strains comes in the form of bacteriocins, antibiotics that act on closely related bacteria. These were found in nearly $40 \%$ of the genomes. Ten genomes encoded type VI secretion systems, which inject effectors into neighboring bacteria (Figure 6). Many genomes had multiple VgrG proteins, the tip of the needle and effector transporter, near large proteins with Rhs repeat domains which may function as bacterial toxins (Figure 6) (57). The Rhs proteins were not limited to the bacteria with type VI secretion systems and may be exported in other ways.

\section{Bacteria-Phage}

Many of the phage we identified appeared to be highly labelled (Figure 4). In the week 6 sample the two most labelled entities were phage (Figure 3). We focused on circularized phage genomes (not integrated into the host genome as a prophage where they could become ${ }^{13} \mathrm{C}$ labelled through host growth alone) as these are likely complete genomes and the product of active infection during our experiment.

We identified Burkholderiales_62_29 as the possible host for one of the most highly labelled phage, Burholderiales phage 68_11, based on the match between a CRISPR-Cas spacer and the complete phage genome. The spacer hit the large terminase subunit with two mismatches (33 bp total). It appears the phage may be capable of a lysogenic life cycle because of the presence of a serine recombinase and a possible induction region consisting of a histone-like protein $\mathrm{H}$ NS and an AT rich region flanking a lambda repressor-like gene.

The other phage-host connection we identified was based on a possible recent lateral gene transfer event. The phage Catenulispora phage 69_17 was highly labelled, and ranked as the $1^{\text {st }}$ and $9^{\text {th }}$ most labelled entity in week 6 and 9 respectively (Figure 3 ). The probable host, Catenulisporales_70_18, encodes a glycoside hydrolase (GH25) which is very similar to one found in the complete phage genome, possibly indicating the phage may have acquired the gene from this bacterial population. The two proteins share $77 \%$ amino acid identity across the protein and a phylogenetic tree of the proteins indicates that the phage and bacterial proteins 
are more related to one another than to other publicly available bacterial sequences (Supplemental figure 6). Homologs exist in many Catenulispora genomes but not in closely related phage genomes, consistent with recent acquisition of the gene by lateral transfer. The acquired gene may be a lysis factor, as $\mathrm{GH} 25$ breaks down peptidoglycan. The phage may have a lysogenic life cycle based on the presence of a gene annotated as a tyrosine recombinase and induction regulation genes, a lambda repressor-like gene and a gene containing a GntR family transcriptional regulator domain and an UTRA domain which regulates the activity of transcription factors in response to small molecules $(58,59)$.

The remaining eight complete phage genomes cannot be linked to a specific host. Many encode DNA methylation genes that may protect the phage DNA from detection or destruction by host antiviral systems. Some phage have additional genes encoding complete restriction modification systems. Several phage genomes encode the ability to manipulate the composition of the bacterial nucleotide pool, including one phage that encodes for the synthesis of 5-hydroxymethyldeoxyuridylate, a special nucleotide that replaces thymine in the phage genome to evade antiviral defense systems. Another phage may encode auxiliary genes, proteins related to those involved in glycosylation and biosynthesis of phosphatidylinositol mannosides. Of the 55 draft bacterial genomes, only two contained identifiable CRISPR-Cas systems, the Burholderiales described above and Acidobacteria_68_21, which encoded two Cas type III-B systems and a type I-C system (Figure 6).

\section{Discussion}

By combining stable isotope probing with genome resolved metagenomics, we identified a number of possible interactions among soil dwelling organisms; these possible interactions become interesting targets for further exploration and testing to determine if they are indeed operating and important in the soil/rhizosphere. The process of density separation yielded better assemblies which likely improved binning by providing more accurate tetranucleotide frequencies and coverage values. Through the generation of genome bins we were able to provide clues regarding the ecological role of these organisms and to develop ideas about the movement of carbon through the system.

A better understanding of holistic rhizosphere ecology may help us develop better agricultural techniques and biotechnological products. Some of the bacteria in our system may be acting as PGPB, through their ability to release nutrients, help in water stressed conditions, or by repelling plant pathogens. By understanding the different trophic networks, we may begin to develop multi-domain plant growth-promoting consortia that could include phage of plant pathogens, fungi, and microeukaryotes. From only 55 bacterial genomes we detected 400 
BGCs, many of these compounds could be novel antibiotics, antifungals, insecticides, herbicides, or pharmaceuticals.

Based on ordination of $\mathrm{rpS} 3$ genes from different samples and isotopically enriched fractions, it appears that the supply of labeled plant root carbon to soil identifies organisms from the background soil community forming visually distinct assemblages of labelled rhizosphere organisms. Also, within the rhizosphere, a large portion of organisms were not directly responsive to the influx of plant-derived carbon and their communities were indistinguishable from bulk samples. Over time, successional shifts may have occurred, but the resolution of this method is not sufficient to detect them. The traditional 16S rRNA gene tag sequencing could identify effects of sampling time point on microbial composition in a parallel experiment (60), but this approach is unable to provide genomic insights. In addition to bacteria, we identified a number of soil eukaryotes, and though this number does not scratch the surface of soil eukaryotic diversity, the assembled metagenomes provide complete $18 \mathrm{~S}$ rRNA sequences without the primer bias inherent with tag-based methods. We identified 10 complete phage genomes which likely represent some of the most abundant phage in our system. This is a small number compared to the total diversity of phage likely present in the soil, yet the complete genomes allow us to predict lysogenic lifestyles and to identify possible hosts of the dominant phage.

By assuming linear growth over the course of the experiment, we can not only estimate enrichment, but also derive gross growth rate estimates for prokaryotes, micro-eukaryotes, and phage that rely on plant-derived carbon. The uncertainties of these estimated rates mirror the uncertainties in measuring the abundance of metagenome-assembled genomes in soil. The use of larger numbers of density fractions results in much reduced uncertainties in growth rate estimates (61). However, as expected, both phage and bacteria showed higher average growth rates than the slower-growing eukaryotes. These quantitative metrics enable linking previously undescribed populations of rhizosphere microbiota to plant-derived C-fluxes in an intact plantsoil environment. Future developments in this technique will allow us to better understand complex carbon utilization networks in soil.

Many of the most highly labelled organisms were those with suspected plant interaction systems and may span the spectrum from mutualist to pathogen. By analyzing genomes with $>70 \%$ completeness we were able to not only look for genes or pathways involved in interaction but also investigate the genomic context for additional information to help predict the purpose of these genes $(62,63)$. For instance, in the Streptomyces_71_13 genome the ACC deaminase gene is adjacent to plant cell wall hydrolysis genes and the biosynthetic pathway for producing ectoine, a compatible solute common in PGPB (40). This region of the genome may allow the 
limiting of a stress response in the plant by lowering ethylene levels and producing an osmoprotectant which would ensure greater plant growth $(64,65)$. The plant cell wall digestion enzymes may enable this PGPB to invade the plant to form a closer mutualistic association with the roots. Apart from that specific region of the genome, Streptomyces_71_13 also encodes a number of other pathways and genes known to be important in PGPB including the production of indole-3-acetic acid and 2,3-butanediol. The possible close association with plant growth promotion may explain why Streptomyces_71_13 was the most labelled entity in week 9.

In addition to possible PGPB we also identified probable plant pathogens. Based on the presence of a type III secretion system and plant effector proteins, Burkholderiales_62_29 may act as a plant pathogen, which may have enabled the assimilation of large amounts of plantderived carbon making this genome the $17^{\text {th }}$ most labelled entity in week 6 . To further support this hypothesis, we referred to the transcription of the effector proteins from a related study of the Avena rhizosphere metatranscriptome which used the Burkholderiales_62_29 genome as a reference, eight of the 58 effectors were statistically upregulated in the rhizosphere when compared to bulk soil transcription (66). In addition to bacteria-plant pathogens, we noted a possible plant-eukaryote interaction. We identified a labelled Fusarium $s p$.

(SM_10888_Uncultured_Fungi) in the rhizosphere samples which likely obtained plant-derived carbon directly from the plant through infection.

It appears that not all bacteria growing on root-derived $\mathrm{C}$ have identifiable genes that predict a close relationship with the plant. The Stenotrophomonas_67_7, Massilia_66_12, and Burkholderiales_70_21 bins were some of the most highly labelled bins, despite encoding few identifiable interactions systems. Bacteria from these genera are known to be fast-growing soil and rhizosphere associated organisms (67-70). Fast growing organisms may be well positioned to take advantage of the abundance of resources in the rhizosphere.

In addition to plant interaction systems, we also identified genes and pathways that may mediate connections between bacteria and non-plant soil eukaryotes. Several of the eukaryotes we identified were labelled with plant-derived ${ }^{13} \mathrm{C}$, including two nematodes, a rotifer and a rhizaria. Based on phylogeny, these microeukaryotes likely have a bacterivorous lifestyle, and thus probably consumed rhizosphere bacteria living off plant-derived carbon. Several bacterial genes encoded systems that may act as grazing deterrents, for instance the pathway to produce $\mathrm{HCN}$ which acts as a nematicidal agent (71). In addition to a type III secretion system with an unknown target, Variovorax_paradoxus_68_14 encodes genes for production of EPS that may defend against predation by micro-eukaryotes, bacteria and phage, provide desiccation protection, improve plant symbiosis, protect the cells from antibiotics and trap nutrients. Bacteria with genomes that encode a large number of fungal cell wall hydrolysis genes may 
obtain carbon from fungal necromass or actively antagonize living fungi through digestion of their cell walls (72).

In the bacterial genomes we also identified possible mediators of bacteria-bacteria communication and competition. In a previous publication we documented the complete genome of a Saccharibacteria that stole or scavenged nucleotides from rhizosphere bacteria that consumed plant-derived carbon and thus became labelled themselves (38). In labelled genomes we identified many signaling compounds and quorum quenching genes, although at this time we cannot verify their purpose, though it appears communication is likely critical for life in soil (73). The number and distribution of inter-bacterial killing systems in labelled genomes may indicate active competition for resources or space in the rhizosphere. The BGCs that were near genes for plant cell wall depolymerization could produce bioactive compounds that aid in defeating plant defenses or deter other bacteria that could consume the now soluble pool of sugars or prevent other bacteria from colonizing the open plant wounds that they themselves occupy.

One of the most intriguing genomes we reconstructed is for an Acidobacterium. The Acidobacteria_68_21 genome encodes a flexible metabolism and many defensive capabilities, CRISPR Cas systems, insecticidal proteins, and 40 BGCs. While this genome was not labelled, it was one of the most abundant bacterium in bulk soil and these defense systems may serve to protect this dominant bacterium from grazing or parasitism.

In this study we traced fixed carbon from the plant into bacterial genomes, and finally into phage genomes. This enabled us to identify the most active phage in the rhizosphere. We infer that the complete phage genomes are derived from phage particles or phage in the process of replication because of their circularized genomes, rather than phage integrated into bacterial genomes. Interestingly, the two of the most highly labeled phage were more highly isotopically labeled than their bacterial hosts. It is likely that recently synthesized nucleotide pools are more highly labelled that other cell structural components, and these nucleotides were shunted directly into the replicating phage genomes. The presence of highly labelled phage implies that phage predation may be a major source of bacterial death, and thus nutrient cycling, in the rhizosphere.

By tracing the movement of the carbon from the plant into the soil community we can begin to understand rhizosphere ecology, which in turn informs us about the carbon cycle in soil. The possible interactions that we identify in rhizosphere soil have the ability to impact plant growth and shape the flow and stabilization of carbon in soil. Lysis of bacteria by phage or interbacterial killing systems may release easily metabolized compounds that could be respired 
and returned to the atmosphere. Bacteria may contribute to soil aggregate stability and carbon stabilization through the production of EPS (74). PGPB could enable the plant to fix more $\mathrm{CO}_{2}$, ultimately increasing the amount of carbon introduced into the soil (75). Only through a better understanding of the interdomain interactions occurring in soil can we begin to understand the functioning of soil.

\section{Conclusions}

Genome resolved metagenomics applied in the context of a SIP study generated insights into the possible interactive capabilities encoded by the genomes of bacteria, including the subset of soil bacteria that rapidly grow on plant-derived carbon compounds. We thus identified organisms and mechanisms of potential interaction that provide fertile topics for further exploration and verification. Long term, understanding of soil interaction networks may provide pathways to improve plant primary production and carbon compound sequestration in soil.

\section{Methods}

\section{Labelling}

Growing and labelling procedures have been described previously (38). Briefly, soil was collected from the University of California Hopland Research and Extension Center (Hopland, CA, USA), from a field dominated by Avena spp. The soil is a fine-loamy, mixed, active, mesic Typic Haploxeralf $(76,77)$. Microcosms and plant growth conditions have been documented previously (60). A soil sample was collected after microcosm preparation but before planting to represent our time 0 sample. A single $A$. fatua plant was grown in a labeling chamber maintained at $400 \mu \mathrm{L} / \mathrm{L} \mathrm{CO}_{2}$, with native $\mathrm{CO}_{2}$ replenished with 99 atom\% ${ }^{13} \mathrm{CO}_{2}$. After six and nine weeks microcosms were destructively harvested. The rhizosphere sample consisted of soil attached to the root after shaking and the bulk soil was collected from a root exclusion mesh bag $(1 \mu \mathrm{m})$. Rhizosphere soil was washed off the root and DNA was extracted from $0.5 \mathrm{~g}$ of soil using a phenol:chloroform extraction (60).

\section{Density separation}

We used a $\mathrm{CsCl}$ density gradient centrifugation to separate the DNA based on density. Methods have been described previously (78). Briefly, $5.5 \mu \mathrm{g}$ of DNA was incorporated into a gradient buffer with a density of $1.735 \mathrm{~g} / \mathrm{mL}$. The solution was spun in ultracentrifuge tubes (Beckman Coulter Quick-Seal, $13 \times 51 \mathrm{~mm}$ ) in an Optima L-90K ultracentrifuge (Beckman Coulter, Brea, California, USA) using a VTi65.2 rotor at $44,000 \mathrm{rpm}\left(176,284 \mathrm{RCF}_{\text {avg }}\right)$ at $20^{\circ} \mathrm{C}$ for $109 \mathrm{~h}$ with maximum acceleration and braking of the rotor to maintain the integrity of the density separations. The gradient was then gently separated into $\sim 32$ fractions using a syringe pump delivering light mineral oil. Each fraction $(\sim 144 \mu \mathrm{L})$ was measured for density using an AR200 digital refractometer (Reichert Inc., Depew, New York, USA). Then DNA was precipitated and 
quantified as previously described (78). Fractions were then binned based on density and by comparison between the rhizosphere samples and the associated bulk soil (light $=1.692-1.737$ $\mathrm{g} / \mathrm{mL}$; middle $=1.738-1.746 \mathrm{~g} / \mathrm{mL}$; heavy $=1.747-1.765 \mathrm{~g} / \mathrm{mL}$; Supplemental figure 1 and Supplemental table 1).

\section{Sequencing}

Each fraction was sequenced at the UC Davis Genome Center on an Illumina HiSeq 3000 (Illumina Inc., Hayward, California, USA) with paired-end libraries prepared with the Kapa Hyper protocol and a read length of $150 \mathrm{bp}$.

\section{Sequence preparation and analysis}

Reads were trimmed using Sickle (https://github.com/najoshi/sickle) and BBtools (https://sourceforge.net/projects/bbmap/) was used to remove Illumina adapters and trace contaminants. Each sample was assembled individually using IDBA-UD (-step 20, -maxk 140, mink 40) (79). Only scaffolds larger than 1000 bp were included in future analyses. Genes were predicted using Prodigal (80). The ORFs were annotated using a combined approach. Sequence similarity searches were performed using USEARCH (81) against UniRef100 (82), Uniprot (83), and the KEGG (84) databases. Additional gene annotations were done using HMMs that were constructed based on KEGG Orthologies. All proteins assigned to a KO were clustered using $\mathrm{MCL}$ (85) with inflation parameter (-I) of 1.1, based on global percent identity. Clusters were aligned using MAFFT v7 (86), and HMMs were constructed using the HMMER suite (87). Protein domain level analysis was conducted using InterProScan (88). Carbohydrate active enzymes were identified using dbCAN (89). Secondary metabolite clusters were found using antiSMASH (90). tRNAs were predicted using tRNAScan-SE (91). The 16S and 18S rRNA sequences were found and aligned using ssu_tree.py (https://github.com/christophertbrown/bioscripts27). Eukaryotic $18 \mathrm{~S}$ rRNA genes were dereplicated and clustered at $98 \%$ nucleic acid identity representing a possible species level designation $(92,93)$, aligned using SSU-ALIGN $(94)$ and trees were generated using RAxML on CIPRES $(95,96)$. Genomes were binned using a combined approach. We used abawaca (https://github.com/CK7/abawaca), MaxBin2 (97), and MetaBAT (98), the best bins were chosen using DAS Tool (99). Further genome curation and binning was done manually on ggKbase (http://www.ggkbase.berkeley.edu). Bins were dereplicated to species level based on rpS3 and 16S rRNA sequence phylogeny.

The rpS3 genes were identified, dereplicated to species level (99\% nucleotide identity), and the longest scaffold was chosen using rpS3_trckr (https://github.com/AJProbst/rpS3 trckr). Each sample was mapped to each scaffold using Bowtie2 (--sensitive and --rfg 200,300) and the reads were filtered for two mismatches and the coverage was calculated using calculate_breadth.py (https://github.com/banfieldlab/mattolm-public-scripts/blob/master/calculate breadth.py) 
(100). The coverage values for the rpS3 scaffolds were normalized for total read depth from the corresponding sample. The principal coordinate analysis was conducted in the R programming environment with the vegan package $(101,102)$. The $R$ script is publicly available (103). RpS3 amino acid sequences were aligned using MAFFT v7.402 (86) with the E-INS-i options on Cipres (96). Trees were generated on Cipres using RaxML with the JTT protein substitution model and figures were generated using $\operatorname{iTOL}(95,96,104)$.

Phage genomes were found using VirSorter and manually on ggKbase (105). Phage genome completeness was checked by mapping reads, as described above, and visualizing on Geneious (106). Circularized phage genomes will have reads paired across the entire span of the scaffold without repetitive elements on the end of the scaffold which could cause long paired reads instead of a circular sequence. CRISPR spacers were found using CRISPRDetect (107).

\section{Enrichment and qSIP}

The coverage and relative abundance of the soil organisms was calculated based on mapping reads using Bowtie2 (--sensitive and --rfg 200,300) (100). For bacterial bins the reads were mapped to all scaffolds in the bin, for eukaryotes the reads were mapped to the whole scaffold containing the 18S rRNA gene, and complete phage genomes were mapped to. Reads were filtered for two mismatches and the coverage was calculated using calculate_breadth.py (https://github.com/banfieldlab/mattolm-public-scripts/blob/master/calculate breadth.py).

The coverage values were normalized for total read depth from the corresponding sample.

We estimated the atom percent excess (APE) ${ }^{13} \mathrm{C}$ enrichment for each taxon following the procedures detailed in Hungate et al. (2015), with the following adjustments for metagenomeassembled genomes instead of 16S rRNA genes. Previous qSIP experiments have relied on amplicon sequencing of the 16SrRNA gene to estimate the relative abundances of bacterial and archaeal taxa. Those relative abundances were then converted to estimates of absolute abundance by multiplying by the total number of $16 \mathrm{~S}$ rRNA gene copies using the universal 16S rRNA primer for qPCR for each density fraction in each replicate gradient. Here, we used the relative coverage (i.e., coverage normalized for read depth) of metagenome-assembled genomes as a proxy for relative abundance and total DNA concentration in place of total $16 \mathrm{~S}$ copies in order to calculate a metric of abundance $(y)$ for each taxon $(i)$ in each density fraction $(k)$, of each replicate $(j)$ as:

$$
y_{i j k}=p_{i j k} \cdot f_{j k}
$$

where $p$ is relative coverage and $f$ is total DNA concentration. This metric of taxon-specific abundance $(y)$ is imperfect because total DNA concentration in the rhizosphere presumably represents many more taxa beyond the metagenome-assembled genomes and eukaryotic scaffolds. 
Analyses were conducted separately for the week 6 and week 9 data. For each time point, we used the bulk soil data from that week as the unlabeled treatment. This experiment was not replicated, so we were unable to calculate confidence intervals for $A P E{ }^{13} C$, an approach used previously to estimate minimum detectable differences in isotope incorporation (34). However, the relationship between rank and value of $A P E{ }^{13} \mathrm{C}$ exhibited a spline function (Supplemental figure 7), suggesting a threshold above which label incorporation was detectable above background variation in qSIP-derived estimates of ${ }^{13} \mathrm{C}$ uptake. We used breakpoint analysis to test for a spline function, and to identify a threshold value above which ${ }^{13} \mathrm{C}$ incorporation could be reasonably inferred. We used the "segmented" package in $\mathrm{R}$, and the segmented function to identify the breakpoint, with the Davies test for significance. We focused this analysis on the 90 taxa exhibiting the lowest values of qSIP-estimated ${ }^{13} \mathrm{C}$ atom percent excess (i.e., from ranks 190), thereby avoiding more enriched regions where the slope of the rank-APE relationship declined (Supplemental figure 7B). Including the high values skewed the estimate of the breakpoint to near 0 APE, whereas focusing on the data around the visually obvious breakpoint of interest resulted in a more conservative estimate of the threshold. The breakpoint was identified at rank 71.1, with a standard error in this estimate of 0.6. We used the breakpoint plus three times the standard error (the upper $99.7 \%$ confidence limit of the breakpoint estimate) to identify the threshold above which ${ }^{13} \mathrm{C}$ uptake could be reasonably inferred. The atom percent excess ${ }^{13} \mathrm{C}$ value associated with the threshold was $2.5 \%$. Thus, we interpreted values above that APE value as having detectably incorporated the tracer. Note, this is somewhat lower than threshold values estimated using confidence intervals calculated from replicated measurements ( $5.6 \%$ for ${ }^{13} \mathrm{C}$ in Hungate et al. AEM).

\section{Declarations}

Acknowledgements: This work was made possible by samples and expertise provided by personnel at the Hopland Research and Extension Center (Hopland, CA, USA). Plant growth and labeling was conducted at the UC Berkeley Oxford Facility. Labelling, sampling efforts, and technical expertise were provided by Katerina Estera-Molina and Donald J. Herman. Sequencing was done at the UC Davis Genome Center and technical advice was provided by Lutz Froenicke. The HMM pipeline was developed by Dr. David Burstein.

Funding: This research was supported by the U.S. Department of Energy Office of Science, Office of Biological and Environmental Research Genomic Science program under Awards DESC0010570 and DE-SC0016247 to MKF, DE-SC10010566 to JFB, and DE-SC0020172 to BAH and SCW1589 and SCW1632 to J.P-R. AJP was supported by the German Science Foundation under DFG1603-1/1. Work conducted at Lawrence Livermore National Laboratory was contributed under the auspices of the US Department of Energy under Contract DE-AC52-07NA27344. EPS 
was supported by a grant from the National Science Foundation Graduate Research Fellowships Program and by the National Science Foundation CZP EAR-1331940 grant for the Eel River Critical Zone Observatory.

Contributions: SS and MKF designed the labeling experiment. SS carried out the labeling. ES and SJB conducted the density centrifugation. BJK and BAH conducted the qSIP and growth rate analyses and interpretation. EPS, MKF, and JFB analyzed the data, with input from AJP and JP. EPS, MKF, and JFB wrote the manuscript and all authors read and approved the final manuscript.

Data availability: The sequences used in this study will be made publicly available upon acceptance of the manuscript.

Ethics approval and consent to participate: Not applicable.

Consent for publication: Not applicable.

\section{References}

1. Bahram M, Hildebrand F, Forslund SK, Anderson JL, Soudzilovskaia NA, Bodegom PM, BengtssonPalme J, Anslan S, Coelho LP, Harend H, Huerta-Cepas J, Medema MH, Maltz MR, Mundra S, Olsson PA, Pent M, Põlme S, Sunagawa S, Ryberg M, Tedersoo L, Bork P. 2018. Structure and function of the global topsoil microbiome. Nature 560:233-237.

2. Delgado-Baquerizo M, Oliverio AM, Brewer TE, Benavent-González A, Eldridge DJ, Bardgett RD, Maestre FT, Singh BK, Fierer N. 2018. A global atlas of the dominant bacteria found in soil. Science 359:320-325.

3. Gao C, Montoya L, Xu L, Madera M, Hollingsworth J, Purdom E, Hutmacher RB, Dahlberg JA, Coleman-Derr D, Lemaux PG, Taylor JW. 2019. Strong succession in arbuscular mycorrhizal fungal communities. ISME J 13:214-226.

4. Taylor DL, Walters WA, Lennon NJ, Bochicchio J, Krohn A, Caporaso JG, Pennanen T. 2016. Accurate estimation of fungal diversity and abundance through improved lineage-specific primers optimized for Illumina amplicon sequencing. Appl Environ Microbiol 82:7217-7226.

5. Butterfield CN, Li Z, Andeer PF, Spaulding S, Thomas BC, Singh A, Hettich RL, Suttle KB, Probst AJ, Tringe SG, Northen T, Pan C, Banfield JF. 2016. Proteogenomic analyses indicate bacterial methylotrophy and archaeal heterotrophy are prevalent below the grass root zone. PeerJ 4:e2687.

6. Diamond S, Andeer PF, Li Z, Crits-Christoph A, Burstein D, Anantharaman K, Lane KR, Thomas BC, Pan C, Northen TR, Banfield JF. 2019. Mediterranean grassland soil C-N compound turnover is dependent on rainfall and depth, and is mediated by genomically divergent microorganisms. Nat Microbiol 1.

7. White RA, Bottos EM, Roy Chowdhury T, Zucker JD, Brislawn CJ, Nicora CD, Fansler SJ, Glaesemann KR, Glass K, Jansson JK. 2016. Moleculo Long-Read Sequencing Facilitates Assembly and Genomic Binning from Complex Soil Metagenomes. mSystems 1:e00045-16.

8. Kroeger ME, Delmont TO, Eren AM, Meyer KM, Guo J, Khan K, Rodrigues JLM, Bohannan BJM, Tringe SG, Borges CD, Tiedje JM, Tsai SM, Nüsslein K. 2018. New Biological Insights Into How Deforestation in Amazonia Affects Soil Microbial Communities Using Metagenomics and Metagenome-Assembled Genomes. Front Microbiol 9:1635.

9. Xue Y, Jonassen I, Øvreås L, Taş N. 2019. Bacterial and Archaeal Metagenome-Assembled 
Genome Sequences from Svalbard Permafrost. Microbiol Resour Announc 8:e00516-19.

10. Tyc O, Song C, Dickschat JS, Vos M, Garbeva P. 2017. The Ecological Role of Volatile and Soluble Secondary Metabolites Produced by Soil Bacteria. Trends Microbiol 25:280-292.

11. Crits-Christoph A, Diamond S, Butterfield CN, Thomas BC, Banfield JF. 2018. Novel soil bacteria possess diverse genes for secondary metabolite biosynthesis. Nature 558:440-444.

12. Emerson JB, Roux S, Brum JR, Bolduc B, Woodcroft BJ, Jang H Bin, Singleton CM, Solden LM, Naas $A E$, Boyd JA, Hodgkins SB, Wilson RM, Trubl G, Li C, Frolking S, Pope PB, Wrighton KC, Crill PM, Chanton JP, Saleska SR, Tyson GW, Rich VI, Sullivan MB. 2018. Host-linked soil viral ecology along a permafrost thaw gradient. Nat Microbiol 3:870-880.

13. Starr EP, Nuccio EE, Pett-Ridge J, Banfield JF, Firestone MK. 2019. Metatranscriptomic reconstruction reveals RNA viruses with the potential to shape carbon cycling in soil. Proc Natl Acad Sci 116:25900 LP-25908.

14. Trubl G, Jang H Bin, Roux S, Emerson JB, Solonenko N, Vik DR, Solden L, Ellenbogen J, Runyon AT, Bolduc B, Woodcroft BJ, Saleska SR, Tyson GW, Wrighton KC, Sullivan MB, Rich VI. 2018. Soil Viruses Are Underexplored Players in Ecosystem Carbon Processing. mSystems 3:e00076-18.

15. Chen L, Xu J, Feng Y, Wang J, Yu Y, Brookes PC. 2015. Responses of soil microeukaryotic communities to short-term fumigation-incubation revealed by MiSeq amplicon sequencing. Front Microbiol 6:1149.

16. Lara E, Berney C, Harms H, Chatzinotas A. 2007. Cultivation-independent analysis reveals a shift in ciliate $18 \mathrm{~S}$ rRNA gene diversity in a polycyclic aromatic hydrocarbon-polluted soil. FEMS Microbiol Ecol 62:365-373.

17. Crossley D, Blair JM. 1991. A high-efficiency, "low-technology" Tullgren-type extractor for soil microarthropods.

18. Macfadyen A. 1953. Notes on Methods for the Extraction of Small Soil Arthropods. J Anim Ecol 22:65.

19. Warmink JA, van Elsas JD. 2009. Migratory Response of Soil Bacteria to Lyophyllum sp. Strain Karsten in Soil Microcosms. Appl Environ Microbiol 75:2820-2830.

20. Deveau A, Antony-Babu S, Le Tacon F, Robin C, Frey-Klett P, Uroz S. 2016. Temporal changes of bacterial communities in the Tuber melanosporum ectomycorrhizosphere during ascocarp development. Mycorrhiza 26:389-399.

21. Ashelford KE, Day MJ, Fry JC. 2003. Elevated abundance of bacteriophage infecting bacteria in soil. Appl Environ Microbiol 69:285-289.

22. Yang A, Liu N, Tian Q, Bai W, Williams M, Wang Q, Li L, Zhang WH. 2015. Rhizosphere bacterial communities of dominant steppe plants shift in response to a gradient of simulated nitrogen deposition. Front Microbiol 6:789.

23. Bonfante P, Genre A. 2010. Mechanisms underlying beneficial plant-fungus interactions in mycorrhizal symbiosis. Nat Commun 1:48.

24. Schubotz F, Hays LE, Meyer-Dombard DR, Gillespie A, Shock EL, Summons RE. 2015. Stable isotope labeling confirms mixotrophic nature of streamer biofilm communities at alkaline hot springs. Front Microbiol 6:42.

25. Godwin S, Kang A, Gulino L-M, Manefield M, Gutierrez-Zamora M-L, Kienzle M, Ouwerkerk D, Dawson K, Klieve A V. 2014. Investigation of the microbial metabolism of carbon dioxide and hydrogen in the kangaroo foregut by stable isotope probing. ISME J 8:1855-1865.

26. Herrmann E, Young W, Rosendale D, Reichert-Grimm V, Riedel CU, Conrad R, Egert M. 2017. RNA-Based Stable Isotope Probing Suggests Allobaculum spp. as Particularly Active Glucose Assimilators in a Complex Murine Microbiota Cultured In Vitro. Biomed Res Int 2017:1-13.

27. Egert M, De Graaf AA, Maathuis A, De Waard P, Plugge CM, Smidt H, Deutz NEP, Dijkema C, De Vos WM, Venema K. 2007. Identification of glucose-fermenting bacteria present in an in vitro 
model of the human intestine by RNA-stable isotope probing. FEMS Microbiol Ecol 60:126-135.

28. Murase J, Shibata M, Lee CG, Watanabe T, Asakawa S, Kimura M. 2012. Incorporation of plant residue-derived carbon into the microeukaryotic community in a rice field soil revealed by DNA stable-isotope probing. FEMS Microbiol Ecol 79:371-379.

29. Wilhelm RC, Singh R, Eltis LD, Mohn WW. 2019. Bacterial contributions to delignification and lignocellulose degradation in forest soils with metagenomic and quantitative stable isotope probing. ISME J 13:413-429.

30. Haichar F el Z, Roncato M-A, Achouak W. 2012. Stable isotope probing of bacterial community structure and gene expression in the rhizosphere of Arabidopsis thaliana. FEMS Microbiol Ecol 81:291-302.

31. Hünninghaus M, Dibbern D, Kramer S, Koller R, Pausch J, Schloter-Hai B, Urich T, Kandeler E, Bonkowski M, Lueders T. 2019. Disentangling carbon flow across microbial kingdoms in the rhizosphere of maize. Soil Biol Biochem 134:122-130.

32. Haig S-J, Schirmer M, D’Amore R, Gibbs J, Davies RL, Collins G, Quince C. 2015. Stable-isotope probing and metagenomics reveal predation by protozoa drives $\mathrm{E}$. coli removal in slow sand filters. ISME J 9:797-808.

33. Lee CG, Watanabe T, Fujita Y, Asakawa S, Kimura M. 2012. Heterotrophic growth of cyanobacteria and phage-mediated microbial loop in soil: Examination by stable isotope probing (SIP) method. Soil Sci Plant Nutr 58:161-168.

34. Hungate BA, Mau RL, Schwartz E, Caporaso JG, Dijkstra P, van Gestel N, Koch BJ, Liu CM, McHugh TA, Marks JC, Morrissey EM, Price LB. 2015. Quantitative microbial ecology through stable isotope probing. Appl Environ Microbiol 81:7570-81.

35. Koch BJ, McHugh TA, Hayer M, Schwartz E, Blazewicz SJ, Dijkstra P, Gestel N, Marks JC, Mau RL, Morrissey EM, Pett-Ridge J, Hungate BA. 2018. Estimating taxon-specific population dynamics in diverse microbial communities. Ecosphere 9.

36. Tsurumaru H, Okubo T, Okazaki K, Hashimoto M, Kakizaki K, Hanzawa E, Takahashi H, Asanome N, Tanaka F, Sekiyama Y, Ikeda S, Minamisawa K. 2015. Metagenomic analysis of the bacterial community associated with the taproot of sugar beet. Microbes Environ 30:63-69.

37. Wylezich C, Papa A, Beer M, Höper D. 2018. A Versatile Sample Processing Workflow for Metagenomic Pathogen Detection. Sci Rep 8:1-12.

38. Starr EP, Shi S, Blazewicz SJ, Probst AJ, Herman DJ, Firestone MK, Banfield JF. 2018. Stable isotope informed genome-resolved metagenomics reveals that Saccharibacteria utilize microbiallyprocessed plant-derived carbon. Microbiome 6:122.

39. Sharon I, Kertesz M, Hug LA, Pushkarev D, Blauwkamp TA, Castelle CJ, Amirebrahimi M, Thomas BC, Burstein D, Tringe SG, Williams KH, Banfield JF. 2015. Accurate, multi-kb reads resolve complex populations and detect rare microorganisms. Genome Res 25:534-543.

40. Probst AJ, Ladd B, Jarett JK, Geller-Mcgrath DE, Sieber CMK, Emerson JB, Anantharaman K, Thomas BC, Malmstrom RR, StiegImeier M, Klingl A, Woyke T, Ryan MC, Banfield JF. 2018. Differential depth distribution of microbial function and putative symbionts through sedimenthosted aquifers in the deep terrestrial subsurface. Nat Microbiol 3:328-336.

41. Sharon I, Morowitz MJ, Thomas BC, Costello EK, Relman DA, Banfield JF. 2013. Time series community genomics analysis reveals rapid shifts in bacterial species, strains, and phage during infant gut colonization. Genome Res 23:111-120.

42. Wang D, Pajerowska-Mukhtar K, Culler AH, Dong X. 2007. Salicylic acid inhibits pathogen growth in plants through repression of the auxin signaling pathway. Curr Biol 17:1784-90.

43. Balashova N V., Stolz A, Knackmuss HJ, Kosheleva IA, Naumov A V., Boronin AM. 2001. Purification and characterization of a salicylate hydroxylase involved in 1-hydroxy-2-naphthoic acid hydroxylation from the naphthalene and phenanthrene-degrading bacterial strain 
Pseudomonas putida BS202-P1. Biodegradation 12:179-188.

44. Mur LAJ, Carver TLW, Prats E. 2006. NO way to live; the various roles of nitric oxide in plantpathogen interactions. J Exp Bot 57:489-505.

45. Farag MA, Ryu C-M, Sumner LW, Paré PW. 2006. GC-MS SPME profiling of rhizobacterial volatiles reveals prospective inducers of growth promotion and induced systemic resistance in plants. Phytochemistry 67:2262-2268.

46. Ryu C-M, Farag MA, Hu C-H, Reddy MS, Wei H-X, Pare PW, Kloepper JW. 2003. Bacterial volatiles promote growth in Arabidopsis. Proc Natl Acad Sci 100:4927-4932.

47. Alori ET, Glick BR, Babalola OO. 2017. Microbial Phosphorus Solubilization and Its Potential for Use in Sustainable Agriculture. Front Microbiol 8:971.

48. Cervini-Silva J, Kearns J, Banfield J. 2012. Steady-state dissolution kinetics of mineral ferric phosphate in the presence of desferrioxamine- $\mathrm{B}$ and oxalate ligands at $\mathrm{pH}=4-6$ and $\mathrm{T}=24 \pm 0.6^{\circ} \mathrm{C}$. Chem Geol 320-321:1-8.

49. Nazir R, Mazurier S, Yang P, Lemanceau P, van Elsas JD. 2017. The ecological role of type three secretion systems in the interaction of bacteria with fungi in soil and related habitats is diverse and context-dependent. Front Microbiol 8:38.

50. Green ER, Mecsas J. 2016. Bacterial Secretion Systems: An Overview. Microbiol Spectr 4.

51. Chen Y, Li B, Cen K, Lu Y, Zhang S, Wang C. 2018. Diverse effect of phosphatidylcholine biosynthetic genes on phospholipid homeostasis, cell autophagy and fungal developments in Metarhizium robertsii. Environ Microbiol 20:293-304.

52. Rittenour WR, Chen M, Cahoon EB, Harris SD. 2011. Control of Glucosylceramide Production and Morphogenesis by the Bar1 Ceramide Synthase in Fusarium graminearum. PLoS One 6:e19385.

53. Matz C, Kjelleberg S. 2005. Off the hook - How bacteria survive protozoan grazing. Trends Microbiol 13:302-307.

54. Berne C, Ducret A, Hardy GG, Brun Y V. 2015. Adhesins Involved in Attachment to Abiotic Surfaces by Gram-Negative Bacteria. Microbiol Spectr 3.

55. Chen W-J, Hsieh F-C, Hsu F-C, Tasy Y-F, Liu J-R, Shih M-C. 2014. Characterization of an insecticidal toxin and pathogenicity of Pseudomonas taiwanensis against insects. PLoS Pathog 10:e1004288.

56. Esmaeel $Q$, Pupin M, Kieu NP, Chataigné G, Béchet $M$, Deravel J, Krier F, Höfte M, Jacques P, Leclère V. 2016. Burkholderia genome mining for nonribosomal peptide synthetases reveals a great potential for novel siderophores and lipopeptides synthesis. Microbiologyopen 5:512-26.

57. Ho BT, Dong TG, Mekalanos JJ. 2014. A view to a kill: The bacterial type VI secretion system. Cell Host Microbe 15:9-21.

58. Gordon BRG, Imperial R, Wang L, Navarre WW, Liu J. 2008. Lsr2 of Mycobacterium represents a novel class of H-NS-like proteins. J Bacteriol 190:7052-7059.

59. Aravind L, Anantharaman V. 2003. HutC/FarR-like bacterial transcription factors of the GntR family contain a small molecule-binding domain of the chorismate lyase fold. FEMS Microbiol Lett 222:17-23.

60. Shi S, Nuccio E, Herman DJ, Rijkers R, Estera K, Li J, da Rocha UN, He Z, Pett-Ridge J, Brodie EL, Zhou J, Firestone M. 2015. Successional Trajectories of Rhizosphere Bacterial Communities over Consecutive Seasons. MBio 6.

61. Sieradzki ET, Koch BJ, Greenlon A, Sachdeva R, Malmstrom RR, Mau RL, Blazewicz SJ, Firestone MK, Hofmockel KS, Schwartz E, Hungate BA, Pett-Ridge J. Measurement Error and Resolution in Quantitative Stable Isotope Probing: Implications for Experimental Design.

62. Huynen M, Snel B, Lathe W, Bork P. 2000. Predicting protein function by genomic context: Quantitative evaluation and qualitative inferences. Genome Res 10:1204-1210.

63. Galperin MY, Koonin E V. 2000. Who's your neighbor? New computational approaches for functional genomics. Nat Biotechnol. Nature Publishing Group. 
64. Singh RP, Shelke GM, Kumar A, Jha PN. 2015. Biochemistry and genetics of ACC deaminase: A weapon to "stress ethylene" produced in plants. Front Microbiol. Frontiers Media S.A.

65. Bouskill NJ, Wood TE, Baran R, Ye Z, Bowen BP, Lim H, Zhou J, Nostrand JD Van, Nico P, Northen TR, Silver WL, Brodie EL. 2016. Belowground Response to Drought in a Tropical Forest Soil. I. Changes in Microbial Functional Potential and Metabolism. Front Microbiol 7:525.

66. Nuccio EE, Starr E, Karaoz U, Brodie EL, Zhou J, Tringe SG, Malmstrom RR, Woyke T, Banfield JF, Firestone MK, Pett-Ridge J. 2020. Niche differentiation is spatially and temporally regulated in the rhizosphere. ISME J.

67. Berg G, Martinez JL. 2015. Friends or foes: Can we make a distinction between beneficial and harmful strains of the Stenotrophomonas maltophilia complex? Front Microbiol 6.

68. Ofek M, Hadar Y, Minz D. 2012. Ecology of Root Colonizing Massilia (Oxalobacteraceae). PLoS One 7:e40117.

69. Singh RP, Jha PN. 2017. The PGPR stenotrophomonas maltophilia SBP-9 augments resistance against biotic and abiotic stress in wheat plants. Front Microbiol 8.

70. Verastegui Y, Cheng J, Engel K, Kolczynski D, Mortimer S, Lavigne J, Montalibet J, Romantsov T, Hall M, McConkey BJ, Rose DR, Tomashek JJ, Scott BR, Charles TC, Neufeld JD. 2014.

Multisubstrate isotope labeling and metagenomic analysis of active soil bacterial communities. MBio 5.

71. Paiva G, Proença DN, Francisco R, Verissimo P, Santos SS, Fonseca L, Abrantes IMO, Morais P V. 2013. Nematicidal Bacteria Associated to Pinewood Nematode Produce Extracellular Proteases. PLoS One 8:e79705.

72. Olanrewaju OS, Glick BR, Babalola OO. 2017. Mechanisms of action of plant growth promoting bacteria. World J Microbiol Biotechnol. Springer Netherlands.

73. Deangelis KM, Lindow SE, Firestone MK. 2008. Bacterial quorum sensing and nitrogen cycling in rhizosphere soil. FEMS Microbiol Ecol 66:197-207.

74. Sher Y, Baker NR, Herman D, Fossum C, Hale L, Zhang X, Nuccio E, Saha M, Zhou J, Pett-Ridge J, Firestone M. 2020. Microbial extracellular polysaccharide production and aggregate stability controlled by switchgrass (Panicum virgatum) root biomass and soil water potential. Soil Biol Biochem 143:107742.

75. Nie M, Bell C, Wallenstein MD, Pendall E. 2015. Increased plant productivity and decreased microbial respiratory $\mathrm{C}$ loss by plant growth-promoting rhizobacteria under elevated CO 2 . Sci Rep 5:1-6.

76. Whitman T, Neurath R, Perera A, Chu-Jacoby I, Ning D, Zhou J, Nico P, Pett-Ridge J, Firestone M. 2018. Microbial community assembly differs across minerals in a rhizosphere microcosm. Environ Microbiol 20:4444-4460.

77. Placella SA, Brodie EL, Firestone MK. 2012. Rainfall-induced carbon dioxide pulses result from sequential resuscitation of phylogenetically clustered microbial groups. Proc Natl Acad Sci 109:10931-10936.

78. Blazewicz SJ, Schwartz E, Firestone MK. 2014. Growth and death of bacteria and fungi underlie rainfall-induced carbon dioxide pulses from seasonally dried soil. Ecology 95:1162-1172.

79. Peng Y, Leung HCM, Yiu SM, Chin FYL. 2012. IDBA-UD: A de novo assembler for single-cell and metagenomic sequencing data with highly uneven depth. Bioinformatics 28:1420-1428.

80. Hyatt D, Chen GL, LoCascio PF, Land ML, Larimer FW, Hauser L. 2010. Prodigal: Prokaryotic gene recognition and translation initiation site identification. BMC Bioinformatics 11:119.

81. Edgar RC. 2010. Search and clustering orders of magnitude faster than BLAST. Bioinformatics 26:2460-2461.

82. Suzek BE, Huang H, McGarvey P, Mazumder R, Wu CH. 2007. UniRef: Comprehensive and nonredundant UniProt reference clusters. Bioinformatics 23:1282-1288. 
83. Magrane M, Consortium UP. 2011. UniProt Knowledgebase: A hub of integrated protein data. Database 2011:bar009-bar009.

84. Ogata H, Goto S, Sato K, Fujibuchi W, Bono H, Kanehisa M. 1999. KEGG: Kyoto encyclopedia of genes and genomes. Nucleic Acids Res 27:29-34.

85. Van Dongen S. 2008. Graph Clustering Via a Discrete Uncoupling Process. SIAM J Matrix Anal Appl 30:121-141.

86. Katoh K, Standley DM. 2013. MAFFT multiple sequence alignment software version 7: Improvements in performance and usability. Mol Biol Evol 30:772-780.

87. Finn RD, Clements J, Eddy SR. 2011. HMMER web server: Interactive sequence similarity searching. Nucleic Acids Res 39:W29-37.

88. Zdobnov EM, Apweiler R. 2001. InterProScan - An integration platform for the signaturerecognition methods in InterPro. Bioinformatics 17:847-848.

89. Yin Y, Mao X, Yang J, Chen X, Mao F, Xu Y. 2012. DbCAN: A web resource for automated carbohydrate-active enzyme annotation. Nucleic Acids Res 40:W445-W451.

90. Medema MH, Blin K, Cimermancic P, de Jager V, Zakrzewski P, Fischbach MA, Weber T, Takano E, Breitling R. 2011. antiSMASH: rapid identification, annotation and analysis of secondary metabolite biosynthesis gene clusters in bacterial and fungal genome sequences. Nucleic Acids Res 39:W339-W346.

91. Lowe TM, Eddy SR. 1996. TRNAscan-SE: A program for improved detection of transfer RNA genes in genomic sequence. Nucleic Acids Res 25:955-964.

92. Hadziavdic K, Lekang K, Lanzen A, Jonassen I, Thompson EM, Troedsson C. 2014. Characterization of the 18s rRNA gene for designing universal eukaryote specific primers. PLoS One 9:e87624.

93. Wu S, Xiong J, Yu YY. 2015. Taxonomic resolutions based on 18S rRNA Genes: A case study of subclass Copepoda. PLoS One 10:e0131498.

94. Nawrocki EP. 2009. Structural RNA Homology Search and Alignment using Covariance Models. PhD thesis 282.

95. Stamatakis A. 2014. RAxML version 8: A tool for phylogenetic analysis and post-analysis of large phylogenies. Bioinformatics 30:1312-1313.

96. Miller MA, Pfeiffer W, Schwartz T. 2010. Creating the CIPRES Science Gateway for inference of large phylogenetic trees2010 Gateway Computing Environments Workshop, GCE 2010.

97. Wu YW, Simmons BA, Singer SW. 2016. MaxBin 2.0: An automated binning algorithm to recover genomes from multiple metagenomic datasets. Bioinformatics 32:605-607.

98. Kang DD, Froula J, Egan R, Wang Z. 2015. MetaBAT, an efficient tool for accurately reconstructing single genomes from complex microbial communities. PeerJ 3:e1165.

99. Sieber CMK, Probst AJ, Sharrar A, Thomas BC, Hess M, Tringe SG, Banfield JF. 2018. Recovery of genomes from metagenomes via a dereplication, aggregation and scoring strategy. Nat Microbiol 3:836-843.

100. Langmead B, Salzberg SL. 2012. Fast gapped-read alignment with Bowtie 2. Nat Methods 9:3579.

101. Oksanen J, Blanchet FG, Friendly M, Kindt R, Legendre P, Mcglinn D, Minchin PR, O'hara RB, Simpson GL, Solymos P, Henry M, Stevens H, Szoecs E, Maintainer HW. 2019. Package "vegan" Title Community Ecology Package.

102. R Core Team. 2014. R: A Language and Environment for Statistical Computing. R Foundation for Statistical Computing, Vienna, Austria.

103. Weinmaier T, Probst AJ, La Duc MT, Ciobanu D, Cheng J-F, Ivanova N, Rattei T, Vaishampayan P. 2015. A viability-linked metagenomic analysis of cleanroom environments: eukarya, prokaryotes, and viruses. Microbiome 3:62.

104. Letunic I, Bork P. 2016. Interactive tree of life (iTOL) v3: an online tool for the display and 
annotation of phylogenetic and other trees. Nucleic Acids Res 44:W242-W245.

105. Roux S, Enault F, Hurwitz BL, Sullivan MB. 2015. VirSorter: mining viral signal from microbial genomic data. PeerJ 3:e985.

106. Kearse M, Moir R, Wilson A, Stones-Havas S, Cheung M, Sturrock S, Buxton S, Cooper A, Markowitz S, Duran C, Thierer T, Ashton B, Meintjes P, Drummond A. 2012. Geneious Basic: An integrated and extendable desktop software platform for the organization and analysis of sequence data. Bioinformatics 28:1647-1649.

107. Biswas A, Staals RHJ, Morales SE, Fineran PC, Brown CM. 2016. CRISPRDetect: A flexible algorithm to define CRISPR arrays. BMC Genomics 17:356. 